\title{
Las mineras de La Toma. Resistencia negra en defensa de la vida y el territorio*
}

\author{
The miner women from de la toma. A Black resistance in defense of life and territory \\ As mineiras de la toma. A resistência negra na defesa da vida e do território
}

\author{
María Camila Bolívar Rocha ${ }^{1}$ \\ (iD http://orcid.org/0000-0003-4637-4131 \\ (D) http://orcidorg/0000-0002-5667-6478 \\ Universidad del Valle, Colombia
}

DOI: http://dx.doi.org/10.21803\%2Fpenamer.10.19.470

Resumen

En este artículo muestra las características de la acción colectiva femenina negra, de un grupo de mujeres mineras de La Toma (Suárez-Cauca), que se movilizan para denunciar las amenazas a la autonomía territorial y a la vida de los pobladores, que se producen por la explotación aurífera en su corregimiento. Una actividad auspiciada por las licencias otorgadas a multinacionales y particulares y por la escasa presencia institucional para controlar a los actores armados y agentes ilegales que se lucran de este negocio. Se muestran principalmente los detonantes para protestar, el modo en que se aprovecha la estructura de oportunidades políticas, durante el gobierno 2010-2014, que propuso la locomotora minera como una de las estrategias para el desarrollo económico; y los principales repertorios de acción utilizados en la contienda. Como recursos metodológicos se realizó una exhaustiva revisión documental de prensa, blogs y comunicados y se entrevistó a siete lideresas. La principal conclusión es que la resistencia civil, cuando involucra elementos étnicos, de género y clase, ligados a su cultura y al lugar de origen, configuran un actor político, que se vale de los símbolos y de su legado histórico para disputar sus derechos.

Palabras clave: Minería, Mujeres, Acción colectiva étnica, Resistencia civil.

\section{Abstract}

In this article, we show the characteristics of the black women's collective action, a group of women miners in La Toma (Suarez-Cauca), who mobilize to denounce threats to territorial autonomy and life of the people, which is produced by gold mining exploitation. This activity was sponsored by licenses granted to corporations and individuals and by a limited institutional presence to control illegal armed actors and agents who profit from this business. It is showed he starting mechanism to protest about the use of the structure of political opportunities during 2010-2014, under the command of Juan Manuel Santos, who proposed the mining locomotive as one of the strategies for economic development, and the mechanisms to avoid such protests. As a methodological resources it was used a comprehensive literature review of the press, blogs and others and an interview with seven leaders. The main conclusion is that civil resistance, involving ethnic, gender and class elements, linked to their culture and place of origin, form a political actor, which uses symbols and historical legacy to contest their rights.

Keywords: Mining, Women, Ethnic collective action, Civil resistance.

\section{Resumo}

Esse texto mostra as características da ação coletiva feminina negra de um grupo de mulheres mineiras de La Toma (Suárez-Cauca), que se mobilizam para denunciar as ameaças à autonomia territorial e a vida dos colonos, que são produzidas pela exploração aurífera em seu corregimento. Uma atividade auspiciada pelas licenças dadas a multinacionais e particulares pela escassa presença institucional para controlar os atores armados e agentes ilegais que lucram com este negócio. Mostra principalmente os feitos desencadeantes para protestar: a maneira pela qual a estrutura das oportunidades políticas, durante o governo 2010-2014, que propôs a locomotiva mineira como uma das estratégias para o desenvolvimento econômico; e os principais repertórios de ação utilizados no concurso. Como recursos metodológicos foi feita uma exaustiva revisão documental de imprensa, blogs e comunicados, e se entrevistou a sete líderes. A principal conclusão é que a resistência civil, quando incorpora elementos étnicos, de gênero e classe, ligados à sua cultura e lugar de origem, configuram um ator político que se vale dos símbolos e de seu legado histórico para disputar os direitos.

Palavras-chave: Mineria, Mulheres, Ação étnica coletiva, Resistência civil.

Cómo referenciar este artículo: Bolívar, M. \& Ibarra, M. (2017). Las mineras de La Toma. Resistencia negra en defensa de la vida y el territorio. Pensamiento Americano, 10(19), 155-174. http://dx.doi.org/10.21803\%2Fpenamer.10.19.470

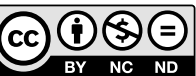

Recibido: Octubre 10 de 2016 • Aceptado: Febrero 10 de 2017

* Este artículo es producto del trabajo de grado titulado de la misma manera y dirigido por María Eugenia Ibarra PhD. en Ciencias Sociales.

1. Licenciada en Lenguas y Socióloga. maria.bolivar@correounivalle.edu.co

2. Socióloga. Master en Investigacion. Doctorado en Ciencias Sociales. Profesora Universidad del Valle.

maria.ibarra@correounivalle.edu.co 


\section{Introducción}

El 17 de noviembre del 2014 un grupo de mujeres procedentes de La Toma, corregimiento de Suárez al Norte del Cauca, emprendieron una movilización de más de $600 \mathrm{~km}$ hacia Bogotá. De acuerdo a su propia descripción se trataba de mujeres negras, que por primera vez salían de sus casas para denunciar la difícil situación que vive su comunidad, por cuenta de las medidas estatales frente a la explotación minera legal e ilegal. Durante las entrevistas se pudo destacar la riqueza de los repertorios utilizados en su recorrido en universidades, centros comunitarios, sindicatos, ONG, casas de familia, lugares de encuentro de organizaciones, la Casa Afro en Bogotá y, por supuesto, en el Ministerio del Interior.

Diez días después llegaron a Bogotá para sentarse en una mesa de interlocución con la Viceministra del Interior, Carmen Inés Vázquez, con quien no lograron ningún acuerdo. Ante este hecho, 17 mineras se tomaron las instalaciones de La Casa de La Giralda, donde funciona el Ministerio del Interior. Decidieron que no volverían a sus casas si el Gobierno Nacional no atendía sus demandas. Pasaron cinco días de frío, hambre y decaimiento físico, presionando el compromiso institucional para ejercer acciones legales contra las empresas constituidas y los mineros ilegales, que se estaban apropiando de sus recursos, al explotar el territorio sin el consentimiento de la comunidad.

En uno de sus comunicados dejaban en- trever que eran mujeres afrodescendientes que estaban allí por el cuidado de la vida, la protección de los territorios ancestrales y para denunciar la minería foránea que a su juicio daña los territorios, desplaza a la población, contamina los ríos, perjudica las prácticas ancestrales y contribuye a debilitar la identidad étnica de los habitantes. Misiva que dirigieron a las mujeres de Colombia y a la opinión pública, para obtener su apoyo en las demandas al Gobierno Central.

Lo que más llama la atención de esta contienda es que haya sido emprendida por mujeres con escasa experiencia participativa en organizaciones, grupos o movimientos sociales, que sean negras, pobres y pobladoras de un lugar alejado, con escasa importancia para el Gobierno local y nacional. Por ello, en la investigación propuesta se trata de comprender ¿Quiénes eran esas mujeres? ¿Cuáles eran sus principales motivaciones para enfrentarse al Gobierno colombiano? ¿Por qué eligen los repertorios de acción que utilizaron en sus movilizaciones? y ¿Cómo aprovecharon la estructura de oportunidades políticas, en adelante llamada EOP, para favorecer su movilización?

Por tal motivo, esta investigación indaga por la participación de las mujeres mineras del corregimiento de La Toma, de Suárez-Cauca, en las movilizaciones colectivas en contra de la minería foránea, durante el primer periodo presidencial de Juan Manuel Santos 2010-2014. Como objetivo se propuso describir las formas de participación de las mujeres que laboran en 
las minas, durante esa coyuntura política, y que se oponen a las directrices estatales, como también a los actores irregulares que explotan los recursos mineros de su territorio. No se puede olvidar que en esta región se vive una confrontación intensa entre las guerrillas, los paramilitares y las Fuerzas Armadas y que la población negra mantiene una disputa permanente con el Estado por el reconocimiento de su posesión legítima del territorio.

Para dar cuenta de estos aspectos nos guiamos por dos categorías sociológicas centrales: el género y la acción colectiva, identificamos la estructura de oportunidades políticas que permitió la movilización de las mujeres y el modo en que la movilización propició nuevas oportunidades políticas para visibilizar sus propuestas. También, se examinan los marcos de referencia usados por las mujeres, tanto en las acciones colectivas que emprendieron, como en los repertorios de movilización que utilizaron. Por último, se caracterizan los repertorios de acción utilizados y sus principales aliados.

Para el desarrollo de esta investigación se realizó una exhaustiva revisión documental en prensa escrita y blogs, la cual se complementa con la información suministrada por seis mujeres de La Toma que fueron entrevistadas (ver Tabla 1), tanto en el lugar de origen, como después de la acción colectiva desplegada, en lugares diferentes. Los instrumentos para recabar la información fueron las fichas de registro, un diario de campo y un guion de entrevista.
Tabla 1. Características de las entrevistadas

Lideresa del Consejo Comunitario de La Toma, 33 años, estudiante de Derecho y ganadora del premio a Defensora de los Derechos Humanos en el 2015.

Lideresa del Consejo Comunitario de La Toma, agro-minera y encargada del proceso de la Consulta Previa para La Toma.

Lideresa de la Organización de mujeres de La Toma, 28 años, integrante del Consejo Comunitario de La Toma, agro-minera.

Integrante del Consejo Comunitario de La Toma, militante del Proceso de Comunidades Negras y estudiante de Comunicación Social en la Universidad del Cauca, 21 años.

Lideresa del Proceso de Comunidades Negras y de la movilización de mujeres, 28 años.

Lideresa de la organización de mujeres de La Toma y agro-minera.

Fuente: Archivo personal. Base de datos creada a partir de la técnica "bola de nieve"

Para la revisión de prensa se eligieron tres periódicos: El diario El Espectador fue escogido por sus informes especiales sobre el tema de la minería. El País, porque informó sobre los principales acontecimientos del suroccidente colombiano y Proclama Caucana, por la difusión de noticias sobre el Norte del Cauca. La selección de noticias se hizo a través de tres categorías: minería, mujeres y movilización, todas con sus respectivas derivaciones y combinaciones. En total se analizaron 56 noticias. En estos registros no se incluye toda la información de contexto que proporcionó la prensa y que aparece en un número mayor de registros noticiosos. Las entrevistas se estructuraron en cuatro ejes: autorreconocimiento étnico y organizativo, principales referencias para emprender las movilizaciones, elementos de contexto y descripción de las acciones colectivas. La información se procesó con el software libre de análisis profesional de texto y datos Multimedia, ATLAS Ti. 


\section{Elementos de contexto}

Según cifras de Centro de Investigación y Educación Popular CINEP (Herrera, García, Coronado, Cadena, Figueroa \& Yepes, 2012), desde 2002 la superficie de hectáreas con título minero pasó de 1,13 millones a 8,53 millones. En el informe El Legado minero de Uribe, publicado por el portal La Silla Vacía se expone que el aumento de la explotación se justificó por el auge en el precio del oro y por las generosas exenciones tributarias, calculadas en 3,5 billones de pesos por el Banco de la República, que otorgó el gobierno de Álvaro Uribe a las multinacionales (Osorio, 2010).

En el periodo de análisis (2010-2014), el presidente de la República Juan Manuel Santos propuso la implementación de la "locomotora de minas y energía" (Plan Nacional de Desarrollo: Prosperidad para todos, 2010), que tenía como propósito aumentar la explotación de recursos demandados por las grandes empresas mineras y respondía al llamado internacional de promover la inversión extranjera directa en el sector minero para contribuir a mejorar los indicadores económicos y el desarrollo (Delgado, 2010).

De acuerdo con Herrera et al. (2012), la plataforma propuesta País Minero permitía la promoción de la minería en Colombia, en el contexto internacional, a pesar de los inconvenientes que implicaba aplicar el modelo extractivista en una de las regiones más biodiversa del mundo, con potencial mega hídrico y con presencia de poblaciones étnicas muy ligadas a sus territorios. Para Herrera et al. (2012) y Cardona (2012), durante esos años, Colombia ocupó primer lugar del continente y el segundo en el mundo en la existencia de conflictos ambientales. Ellos aumentaron entre 2000 y 2012 representaron el 7,61 \% del total de las luchas sociales en el país.

\section{Ubicación de la región donde se desarrolla} el conflicto y aparece la protesta

El municipio de Suárez, hace parte del Norte del Cauca, ubicado entre las cordilleras Central y Occidental (véase Mapa 1). Su mayor afluente hídrico es el río Cauca con el cual estas poblaciones establecen una relación directa, en aspectos económicos, sociales y culturales. En términos económicos, esta zona ha sido impactada por la expansión del cultivo de caña de azúcar, la construcción de la hidroeléctrica de La Salvajina, la minería como nuevo referente económico, una significativa economía ilegal de cultivo de coca y la economía campesina de subsistencia (Guzmán y Rodríguez, 2014). En el tema social, el Norte del Cauca ha sido, históricamente, una de las regiones más afectadas por el proceso colonizador, la esclavitud, la violencia y el conflicto armado. En los últimos 50 años, sus pobladores han sido víctimas del enfrentamiento entre diferentes grupos armados (FARC, ELN, M-19), los paramilitares, las Fuerzas Armadas de Colombia y, de manera más reciente, bandas emergentes y delincuencia. 


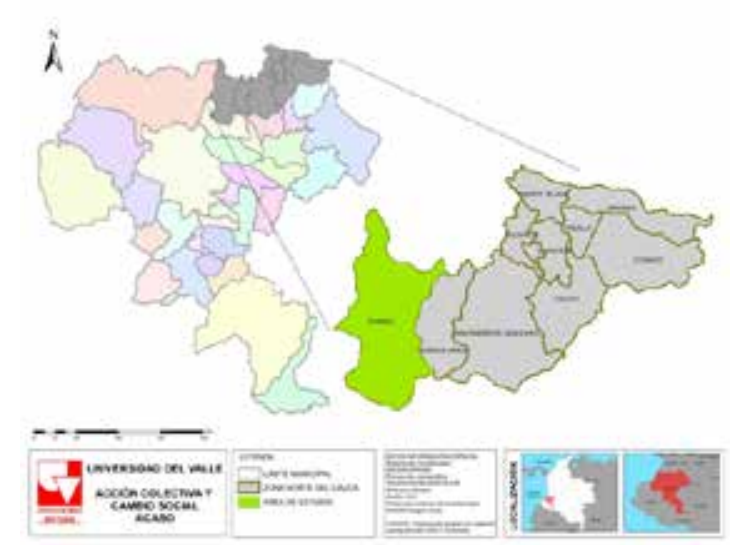

Mapa 1. Localización de Suárez-Cauca

Según Guzmán y Rodríguez (2014), en comunidades campesinas negras dedicadas a la minería tradicional, con niveles de organización media, se presenta un acomodo en medio de la coerción de los armados con alguna presencia estatal, el tipo de actor armado predominante son los paramilitares. En la población proletaria, de predominancia negra, con niveles de organización bajos, se despliega una coerción estatal significativa, que no controla la criminalidad de las bandas asociadas al narcotráfico.

Además de estos “males”, para Macuacé y Cortés (2013), esta región vive la "tragedia de los recursos naturales" de tipo concentrado y localizado. El ascenso de los precios de los minerales en el mundo, ha disparado las expectativas de explotación y atrajo, entre otros, a empresarios migrantes y grupos al margen de la ley, que se apropian del territorio común para intereses económicos particulares a través de acciones institucionalizadas o violentas.

\section{Detonantes para la movilización de las} mujeres de La Toma

Entre los principales antecedentes de movilización de los afrodescendientes en esta zona del país, se destacan:

a) Las movilizaciones por la construcción y operación de la Central Hidroeléctrica La Salvajina. En 1985 algunos pobladores de Suárez y Buenos Aires, Cauca, realizaron plantones en las plazas públicas y frente a las Alcaldías Municipales para protestar y promover jornadas de información sobre la ejecución del megaproyecto de la represa $\mathrm{La}$ Salvajina. A partir de la operación de la hidroeléctrica, la comunidad de La Toma inició un nuevo capítulo de resistencia y lucha en contra del proyecto porque este transformaba su estilo de vida y relación con el territorio (Ararat et al, 2013).

b) El naciente Consejo Comunitario de La Toma y la oposición al proyecto de desviación del río Ovejas. Con la promulgación de la Constitución Política de Colombia en 1991, la cual abre la puerta a la Ley 21 de 1991 -en concordancia con el Convenio 169 de la OIT-y a la Ley 70 de 1993, ambas favorables a los derechos de la población afrodescendiente, se conforma el Consejo Comunitario de La Toma y a partir de este hecho se originaron incipientes formas organizativas de mineros y mujeres. Empezaron con su oposición al transvase del río Ovejas que de acuerdo con los pobladores, amenazaba la subsistencia de los pobladores de La Toma. Ararat et al., 2013). Entre las exigencias que elevaron ante el 
Gobierno estaba la solicitud del proceso de consulta previa autónoma. Las denuncias surtieron efecto y el proyecto se archivó temporalmente.

c) La masacre en el río Naya. A medida que pasaban los años, se fortalecía el proceso organizativo de los pobladores, que coincide con la llegada de los grupos al margen de ley y la imposición de órdenes locales que atemorizaban a los pobladores. Según una de las principales líderes de la zona, la masacre del Naya tiene como antecedente el despojo de tierras que se realizó para la construcción de represa de La Salvajina. Para ella, la arremetida paramilitar, incorporó normas de comportamientos y mandatos para disciplinar a los hombres en sus trabajos y a las mujeres en sus casas. Este aspecto también se señala en Guzmán y Rodríguez (2014), para referirse a la presencia de las Autodefensas Unidas de Colombia, AUC, al Norte del Cauca, que con su ocupación del territorio imponen la violencia.

d) Disputa por el territorio entre la comunidad negra de La Toma y las transnacionales mineras AngloGold Ashanti, Cosigo Resources y Oro Cauca (2004-2008). A medida que estas empresas realizaban la exploración y explotación, autorizada por el Gobierno Central, interferían en la vida comunitaria y trastocaban las relaciones sociales. Atrayendo a la población, usando como estrategia la generación de empleo masivo y la donación de insumos a grupos representativos de la comunidad. De modo similar, maniobraron en el Gobierno lo- cal, asesorando la formulación del Plan de Desarrollo municipal (2002-2006). Para las mujeres, la presencia de estas empresas constituía una amenaza permanente al poder político local, a la economía campesina y a la riqueza minera de su territorio. Estas preocupaciones fueron ampliamente discutidas por sus líderes en el Consejo Comunitario, pero varios de ellos fueron amenazados por grupos al margen de la ley; estigmatizados por los funcionarios ligados a las empresas, que los rotularon de guerrilleros o ambientalistas frustrados. Algunos vecinos, con intereses individualistas, se alinearon a las condiciones que brindaban estas empresas y "con esta actitud redujeron la gravedad de la situación".

e) Desobediencia afro: Orden de desalojo por título minero a Héctor Sarria y Sentencia T-1045A/10 (2010). En 2002, Ingeominas, el Servicio Geológico Colombiano, otorgó la concesión de 99 hectáreas al empresario Héctor Jesús Sarria, para la explotación de un yacimiento de oro, durante 10 años prorrogables (Sentencia T-1045A/10, 2010). Estas tierras están ubicadas en la desembocadura de la quebrada La Turbina. Esta concesión no acreditaba licencia ambiental, ni consulta previa con las comunidades negras que allí residen. Amenazados por la inminente expulsión, dos de sus líderes (un hombre y una mujer) interpusieron una acción de tutela al Estado, en mayo 20 del 2010, "aduciendo vulneración de los derechos: a la vida digna, a la consulta previa, al trabajo, al debido proceso y la autonomía 
e integridad cultural”. Un año más tarde, la Corte Constitucional falló a favor de la comunidad de La Toma y le otorgó el derecho a permanecer en el territorio. Suspendió la licencia al empresario Sarria y cualquier otra que no hubiere sido consultada y aceptada por la comunidad (Sentencia T-1045A/10, 2010).

Los anteriores son los detonantes más importantes para movilizarse, lo que permite señalar que la situación de vulnerabilidad no es reciente y que las amenazas a su autonomía se han convertido en una motivación para emprender acciones colectivas. Desde esta perspectiva, las mujeres comienzan a reconocer sus oportunidades en escenarios organizativos y diseñan estrategias políticas que las promueven como lideresas de la comunidad y las posicionan como protagonistas en el proceso de resistencia, que tuvo lugar durante los años del primer mandato de Juan Manuel Santos y que han hecho visible a su comunidad. En este orden de ideas, la conjunción de factores desestabilizadores de la convivencia, hacen posible la organización y posterior movilización de las mujeres de La Toma.

\section{Mujeres en defensa de la vida y los territo-} rios ancestrales

A continuación, se aludirá a los aspectos concernientes a la apropiación que las mujeres hacen de su territorio a partir de elementos legales, simbólicos, identitarios y étnicos. Mostraremos las principales acciones colectivas de las mineras, en defensa de la vida y del territo- rio ancestral. De igual forma, se presenta una reflexión sobre el significado que adquiere la minería como factor preponderante en la lucha emprendida por ellas y un análisis preliminar de aspectos estructurales dentro del fenómeno estudiado, centrado en la estructura de movilización aprovechada por las mujeres durante los años de estudio. Por último, se dará cuenta de las motivaciones para actuar, los rasgos que adquiere la movilización y las alianzas que establece, los principales oponentes que enfrenta, es decir, el cómo se aprovecha la EOP para actuar.

Territorialidad, identidad étnica y resis-

\section{tencia femenina en La Toma}

Este territorio ha sido habitado por población negra descendiente de liberados de la esclavitud, que han conformado una comunidad que vive y se mantiene libre gracias a sus prácticas tradicionales basadas en la agricultura y la explotación de oro. Irónicamente, el oro que les dio autonomía durante tantos años, hoy pone en riesgo su existencia. Los conflictos que desencadena la explotación aurífera promueven formas de resistencia para defender su territorio, su autonomía e identidad cultural y enfrentarse a enemigos poderosos.

$\mathrm{Al}$ empleo de los recursos legales como los Arts. 7 y 70 de la Constitución Política de Colombia, la Ley 21 de 1991 (Convenio 169 de la OIT) y la Ley 70 y la Ley 99 de 1993, se suman las acciones colectivas no violentas. Tal como planteó Tarrow (1994), estas estrategias son empleadas por personas sin acceso regular a 
instituciones de poder, con objetivos comunes, que exploran oportunidades políticas, creando una identidad forjada a través de métodos no violentos. En su mayoría, las organizaciones que los utilizan lo hacen para enfrentarse a adversarios poderosos; provocan desafíos colectivos a través de una interacción mantenida y el ejercicio continuo de repertorios de acción colectiva, convencionales y disruptivos. Se destacan los de resistencia civil, los cuales se emplean ante el escalonamiento del conflicto armado, que impacta en la población civil, que resulta ser la más afectada por el desplazamiento, la desterritorialización y la muerte (Hernández, 2009).

La resistencia civil es definida como la respuesta colectiva de la población a diferentes modalidades de violencia, la cual requiere de la existencia previa de un proceso organizativo y de planeación, desplegándose dentro del marco constitucional del Estado (Hernández, 2002). La resistencia civil no usa ni la violencia ni la violación de leyes, lo cual no implica una ética pacifista. En sí misma, se enmarca en acciones colectivas de tipo disruptivo que apelan al sentido de justicia de los ciudadanos libres e iguales, demanda la solidaridad y principios de cooperación social que no son tomados en cuenta por los gobernantes (Hernández, 2009).

El uso de estos repertorios ha evitado la irrupción de los actores armados y de agentes privados al territorio y ha fortalecido el proceso organizativo, sobre todo, de las mujeres que se convierten en la vanguardia del Consejo
Comunitario y de las organizaciones sociales creadas por la comunidad. Ellas se exponen, permanentemente, a grandes riesgos y señalan que lo hacen por la defensa de la vida y del territorio. Para hacerlo se han valido de materiales simbólicos y culturales, algunos heredados y otros aprendidos en su contacto con académicas, activistas de otras organizaciones y movimientos sociales y funcionarias, entre otras.

En este artículo tratamos de mostrar cómo ellas aprovechan esos elementos culturales para lograr mayor efectividad en los objetivos que se proponen. Para este propósito nos valemos de los análisis de Angela Davis sobre la experiencia de las mujeres negras en el periodo esclavista, dado que sus argumentos contribuyen a entender las demandas actuales y su sustento cultural. Para esta autora, a ellas nunca se les exigió ser "femeninas". Por el contrario, debían comportarse como sus compañeros varones en las labores agrícolas y mineras. Al ser liberadas, las mujeres negras fueron ubicadas en la última escala de pirámide social, subvaloradas y estereotipadas como promiscuas. Solo se les dio espacio en los trabajos más "sucios" y peor pagados (Davis, 1981). En consecuencia, esta experiencia implicó su estigmatización, exclusión y rechazo. Quizás por esto, hoy ellas se vinculan a organizaciones étnicas, de mujeres y feministas, desde donde exigen sus derechos y reivindican identidades.

En el caso que nos interesa, las mujeres de La Toma se reconocen como dadoras de vida. Se autoidentifican como las llamadas a prote- 
gerla, desde sus roles de madres, hijas, esposas y hermanas; y como cuidadoras de las tradiciones ancestrales y culturales. Por ello, promueven la resistencia por los territorios colectivos como espacio para el ser.

Estas mujeres heredaron de sus madres y abuelas las marcas del sufrimiento esclavista y la decisión resoluta de mantener la libertad, a pesar de las precarias condiciones en las que viven. Desde el tiempo de la esclavitud, se han dedicado a las actividades mineras y agrícolas como sustento, no solo económico, sino también social y cultural. Estas sostienen todo un andamiaje de prácticas sociales, culturales y económicas, que se ha constituido en un saber ancestral, artesanal, que trasciende de generación en generación, tejiendo redes y construyendo comunidad. Para Attilio Bernasconi (2014), estas prácticas son vistas como las herramientas de lucha y resistencia en defensa del territorio heredado, que le permiten a la comunidad permanecer en el tiempo, conservando su identidad, tradición y forma de organización social. En este territorio, ellas hacen resistencia a la precaria presencia estatal y a la amenaza constante de implementar megaproyectos que responden a la idea del desarrollo económico ligado a la explotación de los recursos naturales. Una idea que no comparten porque violan la autonomía, devalúan las tradiciones y fragmentan el territorio ancestral.

Como ellas lo reconocen, tanto las actividades económicas como la vida cotidiana se desarrollan alrededor del río Ovejas, que les permite recrear una identidad emocional ligada a los saberes ancestrales y las tradiciones. Por ello, cuando estas prácticas son amenazadas permiten movilizar a otros pobladores del Corregimiento y no solo a los mineros. Estas lideresas de los procesos organizativos y políticos de La Toma, más allá de defender la minería, pretenden salvaguardar todo lo simbólico que en ella se entreteje. Aquellos sentimientos, prácticas, hábitos y solidaridades configuradas por esta actividad les dan la posibilidad de cohesionarse como grupo étnico. Por eso, para ellas es necesario proteger, cuidar y defender el territorio.

Para nosotras hacer minería ancestral es una forma de sentirnos bien, nos hace sentir orgullosas, si usted ahorita va para el río, usted ve a la gente en su veta, en su tonga [Para los afrodescendientes traduce Minga en la mina]. Viéndolas como un espacio donde encontrarnos ¡Sí, como comunidad!, de trabajar juntos ¡Como comunidad! En la minería nos ayudamos entre todos. -Si entonces alguien no lleva almuerzo al río- todo el mundo ve cómo le ponen de su propio almuerzo y le arman su almuerzo a esa persona. Para mí esos son principios de solidaridad que han hecho que nosotros permanezcamos como comunidad allá (lideresa del Consejo Comunitario de La Toma).

Esa cercanía comunitaria ha favorecido su organización y participación política, cada vez 
más recurren al uso de formatos innovadores para la defensa del territorio y la vida; aprovechan el contexto político favorable a las comunidades étnicas y se apropian de los espacios de discusión con el Gobierno Central y las instancias de toma de decisión; asisten a las audiencias públicas del Congreso de la República, a los encuentros internacionales, promueven marchas intermunicipales, y se valen de aliados influyentes.

A ese empoderamiento que muestran hacia el exterior, se suman los cambios que han afectado las relaciones de género en la comunidad. Su vinculación a la actividad económi$\mathrm{ca}$, no como ayudantes familiares, sino como trabajadoras independientes les ha permitido ganar autonomía económica frente a los varones de sus familias y hogares, lo que les permite negociar con ellos la equidad de género. Este intercambio no está libre de tensiones con los hombres de la comunidad, porque estos se resisten a la competencia económica y a las transformaciones que se producen en la vida cotidiana. Las líderes les restan importancia a esa resistencia, porque la mayoría de ellas ha asumido muchas veces la jefatura de hogar, pues no siempre los varones están presentes como proveedores.

A muchas de nosotras nos ha tocado criar a nuestros hijos e hijas solas. La batea, el almocafre y la pala han sido testigos de ello. El territorio ha sido nuestro compañero y ha estado con nosotras en momentos de alegrías y tristezas (lideresa del Consejo Comunitario de La Toma).
Para estas mujeres la mina es el espacio donde se despojan de las desventajas impuestas por su condición femenina, allí pueden tramitar con los hombres sus derechos sobre el territorio y el trabajo. Tal como se desprende de sus respuestas, la minería tiene para ellas un significado práctico y uno simbólico. Por una parte, es una actividad económica y por la otra una práctica en la que se reproducen los valores de hermandad y solidaridad. Para una lideresa del PCN, la minería es un seguro de vida para su comunidad en la medida que les permite acceder a un recurso que les permitirá mantenerse libres.

Nuestra visión como mujeres es de largo plazo, pensándolo intergeneracionalmente... Pensando ojalá los nietos de nuestros hijos puedan vivir dignamente sin tener que vender su fuerza de trabajo asalariado, a no poder disponer de su tiempo, recibir órdenes, someterse a maltratos, discriminación porque no tienen tierra, no tienen oro, no tienen sembrados (lideresa del Proceso de Comunidades Negras).

A continuación, describimos las estructuras de movilización que utilizaron.

La organización de mujeres: descentralización en el activismo femenino de La Toma

De acuerdo con las entrevistadas, la creación de una organización exclusiva de mujeres responde a las debilidades organizativas del 
Consejo Comunitario de La Toma, que marginaba a las mujeres de los espacios de concertación y toma de decisiones. Situación que generó una oportunidad para las lideresas que participaban en el Consejo, quienes aprovecharon las lecciones aprendidas por otras mujeres negras y la cercanía que habían logrado con una aliada poderosa como Angela Davis, la académica norteamericana.

También se beneficiaron de la coyuntura que provocó el conflicto entre la comunidad y el empresario Héctor Sarria. En este momento, ellas se dieron a la tarea de formar, organizar y movilizar a otras mujeres. Utilizaron el "voz a voz" para conformar un grupo de mujeres. Las asistentes llegaron con la idea de crear una organización productiva, pero con el transcurrir del tiempo, esta fue incorporando los intereses político-culturales. Lo primero que crearon fue la Escuela de Mujeres de La Toma, cuyo propósito central era la creación de apuestas productivas que tomaran en cuenta el valor de lo propio. Más adelante, insistieron en la importancia de luchar por el territorio, la vida, las tradiciones, la autonomía y la identidad, desde su condición de madres, hermanas y esposas.

Este tipo de agrupación, de acuerdo con Tarrow (1994), puede ser clasificada como una “organización de la acción colectiva”, entendiendo por esta una agrupación temprana de gente insatisfecha, que se propone crear células y normas estables, que puede ser controlada por una organización formal o autónoma, bajo el control de un liderazgo, y que se apoya en las redes sociales donde viven o trabajan los militantes. Estos últimos deben lograr la transformación de su confianza mutua en solidaridad.

Comenzamos a crear estrategias de lo que sabemos hacer, varias de ellas son tejedoras y empezaron a hacer bolsos $y$ muñequitas negras y entonces empezaron a poner su parte creativa y a hacer, pero también empezamos a fomentar lo de la finca, entonces vamos a sembrar. Una de ellas tenía tierra y las otras no, entonces puso la tierra como para que todas vayamos y sembremos, entonces hicimos una parcela de plátano, maíz y frijol (lideresa del Consejo Comunitario de La Toma).

La estructura de la Escuela tuvo un viraje cuando esta líder abandona la organización por un embarazo de alto riesgo. En tales circunstancias, el nuevo liderazgo incorpora nuevas metas, tal como informa quien asume el nuevo rol de lideresa del proceso:

La Escuela de Mujeres Negras por el Cuidado de la Vida y los Territorios Ancestrales, tiene el propósito de promover el liderazgo de mujeres de La Toma, que hagan parte del Consejo Comunitario. Esta escuela promoverá nuestros procesos de reivindicación de nuestros derechos étnicos territoriales, a la autonomía y la soberanía alimentaria desde una 
perspectiva negra, comunitaria y femenina (lideresa del Consejo Comunitario de La Toma, ganadora del Premio Defensora de los Derechos Humanos 2015).

50 mujeres integraron esta organización, se reunían cada lunes en la escuela primaria del Corregimiento para tomar clases de diferentes temas. Con el pasar de los meses, se presentan las primeras deserciones, ante las culpas que cargan las mujeres por "abandonar" las tareas del hogar, el cuidado de los menores y de sus maridos. A esta situación se sumó la partida de su lideresa principal, quien decide ingresar a la Universidad en la ciudad de Cali. Con su partida, la organización enfrentó nuevos retos: Varias integrantes se desmotivaron y se hizo evidente su falta de autonomía para continuar con las acciones.

Cuando se rompe el vínculo de la dirección con la base, la organización se debilita. Una vez esta se conectaba de nuevo con la gente, se reactivaban los ánimos. Pero, como plantea Tarrow, estas interacciones deben ser permanentes para favorecer la estructura de la organización. La falta de coordinación, la discontinuidad en los procesos, las enconadas disputas por la toma de decisiones a distancia y el personalismo terminan fracturando cualquier organización, porque las interacciones informales se nutren de los lazos sociales con la gente, con sus hábitos de trabajo y el entusiasmo por planificar y llevar a cabo acciones colectivas (Tarrow, 1994).
Todos estos elementos sirvieron para externalizar la situación de las mujeres de La Toma; para aumentar los aliados influyentes y para motivar la participación de otras mujeres en la organización, pero también debilitaron la movilización de otras personas que consideraban que el personalismo de una de sus lideresas, carismática, que se exponía constantemente a los medios de comunicación masiva, en ámbitos locales, nacionales e internacionales. Su importancia como víctima fue tal que logró ser una de las delegadas a los Diálogos de Paz entre el Gobierno de Colombia y las FARC, en La Habana. Era ponente central en eventos académicos en universidades y centros de investigación en Colombia y Estados Unidos, se destacaba en los encuentros de la ONU y en otros eventos políticos de organizaciones y movimientos sociales solo tenía réditos individuales.

\section{Motivaciones y repertorios de la acción colectiva}

A pesar del contexto de violencias, exclusión, marginación y racismo, las mujeres de La Toma han resistido, creando para ellas y sus familias nuevas condiciones de vida, saberes y formas de ser. Ellas se movilizan, como señalan varias entrevistadas: "porque sabemos lo que es parir, por eso estamos llamadas a defender la vida para dejársela a nuestros hijos". Esto evidencia una estrecha relación entre la preservación de la familia y la defensa del territorio. Algunas veces lo hacen al lado de los hombres y otras en contra de la voluntad de sus esposos o compañeros. Esto no quiere decir que sean 
feministas o que se opongan a la dominación masculina, hay pocos elementos empíricos que permitan interpretar sus reivindicaciones como tales. Más bien, lo que se destaca es la importancia que le dan al legado étnico, un ejemplo de ello es la maternidad y el cuidado por el otro, funciones que no son vistas como impuestas por roles de género tradicionales, sino como elecciones que potencian la independencia de la mujer negra y la anima a ponerse al mando de su propio cuerpo.
Yo creo que el tiempo de los hombres ya pasó, llegó el tiempo de las mujeres, de tomar decisiones serias, decisiones donde lo que prime no sea lo económico, donde no se anteponga la plata sobre la vida, yo creo que con el mismo amor maternal que uno amamanta y cuida a un hijo debe ser el mismo amor maternal que nosotras tenemos que poner para amamantar esta sociedad y para volverla a reorientar (lideresa del Consejo Comunitario de La Toma).

Tabla 2. Características de la acción colectiva de las mujeres de La Toma-Cauca

\begin{tabular}{|c|c|c|c|}
\hline Título & Repertorio & Tipo & Fecha \\
\hline Resistencia civil por desalojo & Bloqueos & Disruptiva & Mayo 2010 \\
\hline Bloqueos a autoridades estatales en contra de desalojo & Bloqueos & Disruptiva & Mayo 2010 \\
\hline Lobby por organizaciones étnicas & Lobby político & Convencional & Mayo 2010 \\
\hline Asamblea permanente interétnica & Asambleas públicas & Disruptiva & Mayo 2010 \\
\hline $\begin{array}{l}\text { Tutela por: vulneración de los derechos "a la vida digna, consulta } \\
\text { previa, al trabajo, debido proceso y a la autonomía e integridad } \\
\text { cultural" }\end{array}$ & Otros & Convencional & Mayo 2010 \\
\hline 1 de mayo & Movilización/plantón & Convencional & Mayo 2010 \\
\hline Manifestación hasta CVC & Movilización/plantón & Disruptiva & Junio 2010 \\
\hline $\begin{array}{l}\text { Audiencia pública en comisión de derechos por el caso de La } \\
\text { Toma }\end{array}$ & Alocuciones públicas & Convencional & Agosto 2010 \\
\hline Visita de Ángella Davis & Encuentros & Disruptiva & Septiembre 2010 \\
\hline Encuentro con personas del África sobre AngloGold & Encuentros & Disruptiva & Octubre 2010 \\
\hline Visibilización de la aprobación de la Sentencia T-1045A/10 & Movilización/plantón & Convencional & Diciembre 2010 \\
\hline 1 de mayo & Movilización/plantón & Convencional & Mayo 2011 \\
\hline Congreso de los pueblos en Cali & Reuniones de protesta & Convencional & Septiembre 2011 \\
\hline Conmemoración de muerte de Robert Guacheta & Homenaje a fallecidos & Convencional & Noviembre 2011 \\
\hline Vigilia Estados Unidos & Movilización/plantón & Disruptiva & Noviembre 2011 \\
\hline Gira por universidades de Estados Unidos & Otros & Convencional & Diciembre 2011 \\
\hline 1 de mayo & Movilización/plantón & Convencional & Mayo 2012 \\
\hline Congreso de los pueblos en Bogotá & Reuniones de protesta & Convencional & Septiembre 2012 \\
\hline Conmemoración de muerte de Robert Guacheta & Homenaje a fallecidos & Convencional & Octubre 2012 \\
\hline Bloqueo a retroexcavadoras en río Ovejas & Bloqueos & Disruptiva & Septiembre 2014 \\
\hline Bloqueo a la Panamericana & Bloqueos & Disruptiva & Octubre 2014 \\
\hline Audiencia pública por minería ilegal en movilización de mujeres & Alocuciones públicas & Convencional & Noviembre 2014 \\
\hline
\end{tabular}




\begin{tabular}{|l|l|l|l|}
\hline \multicolumn{1}{|c|}{ Título } & \multicolumn{1}{c|}{ Repertorio } & \multicolumn{1}{c|}{ Tipo } & \multicolumn{1}{c|}{ Fecha } \\
\hline Encuentros con organizaciones juveniles & Encuentros & Disruptiva & Noviembre 2014 \\
\hline Encuentros con organizaciones de mujeres & Encuentros & Disruptiva & Noviembre 2014 \\
\hline Encuentro con personas en contra de la minería a gran escala & Encuentros & Disruptiva & Noviembre 2014 \\
\hline Actos culturales & Actos públicos simbólicos & Disruptiva & Noviembre 2014 \\
\hline Marchas por tres departamentos & Movilización/plantón & Disruptiva & Noviembre 2014 \\
\hline Toma de espacios públicos & Toma a instalaciones & Disruptiva & Noviembre 2014 \\
\hline Toma de espacios académicos & Toma a instalaciones & Disruptiva & Noviembre 2014 \\
\hline Denuncias públicas & Alocuciones públicas & Disruptiva & Noviembre 2014 \\
\hline Reuniones con aliados & Representaciones en grupo & Disruptiva & \\
\hline Reuniones con representantes del Estado & Representaciones en grupo & Disruptiva & Noviembre 2014 \\
\hline La toma a la casa la Giralda & Toma a instalaciones & Disruptiva & Noviembre 2014 \\
\hline Bloqueo a retroexcavadoras en río Ovejas & Bloqueos & Disruptiva & Diciembre 2014 \\
\hline V Delegación de víctimas en Cuba & Otros & Convencional & Noviembre 2014 \\
\hline Movilización cultural & Movilización/plantón & Convencional & Noviembre 2014 \\
\hline Toma a las instalaciones de INCODER & Toma a instalaciones & Disruptiva & Diciembre 2014 \\
\hline
\end{tabular}

Fuente: Archivo personal. Base de datos creada a partir de las Acciones Colectivas reportadas por las mujeres de La Toma en las entrevistas

En este sentido, ¿Qué es lo que las motiva a desplegar la acción colectiva? "En la motivación se da tránsito de la demanda individual a la colectiva, lo que constituye una de las preguntas centrales de la teoría de movimientos sociales" (Castillo, 2010, p.135). El objetivo del presente acápite es describir esas motivaciones y los repertorios de acción que utilizaron.

El universo de estudio está conformado por 37 acciones colectivas desarrolladas entre los años 2010 al 2014, cuyas motivaciones principales fueron: la defensa de lo propio, desde su situación de mujeres; la defensa del territorio, desde su identidad étnica; las demandas para mejorar la presencia del Estado y la protección de los DDHH (ver Tabla 1).

Una de las claves para analizar las motiva- ciones y los repertorios de acción colectiva de las mujeres negras de La Toma es determinar la función que cumple el género y la etnia en la configuración de estos dos aspectos. En consecuencia, es relevante comprender la influencia de los elementos identitarios étnicos y de género en sus reclamos.

Para la socióloga Avtar Brah en su estudio Cartografías de la diáspora: identidades en cuestión (2011), las circunstancias de partida en una diáspora son tan importantes como las de llegada y asentamiento. Para ella la manera en la que un grupo se «sitúa» en y a través de una amplia gama de discursos, procesos económicos, políticas estatales y prácticas institucionales es crucial para su futuro, esta «inserción» marca cómo el grupo será posicionado relacionalmente en un contexto dado. 
Para el caso de las mujeres de La Toma, el discurso en torno a la diáspora africana se ha incorporado en su autoidentificación, al proveerles un arma de lucha a favor de sus demandas y reivindicaciones, que en principio no son propiamente de género, sino que responden a la necesidad de supervivencia de su comunidad, que las guía a dar prioridad a la defensa del territorio, las prácticas comunitarias, las tradiciones y la cultura que ellos han gestado allí.

Esta es una comunidad que desde el tiempo de la esclavitud ha estado ahí, conservando las prácticas de la minería y de la agricultura, que ante el abandono estatal es lo que le ha permitido permanecer. Es como muy paradójico que después de venir en condición de esclavos, liberarnos nosotros mismos y el Estado habernos dejados solos como un niño huérfano que camine solo, nos vengan a decir que el desarrollo es de todos y que ahora sí importamos (lideresa de la Organización de mujeres de La Toma y del Consejo Comunitario).

Desde esta perspectiva, la diáspora africana ha inspirado una identidad común entre mujeres negras de diferentes latitudes. Para el caso concreto, les ha posibilitado desarrollar mecanismos de resistencia, bajo propuestas subversoras del orden social que las oprime a razón de su condición étnica-racial, de clase y género. Estos mecanismos de resistencia, propuestos por Avtar Brah (2011), se pueden observar en la experiencia de las mujeres de La Toma en: a) La reapropiación del territorio a nivel físico y simbólico, a través de la reorganización de Consejo Comunitario de La Toma, b) La oposición a la cultura dominante, en función de construir su identidad para no ser definidas por $y$ en beneficio de otros, gracias a la Escuela para mujeres de La Toma, c) La conversión de los espacios de dominación femenina en lugares de transformación personal y colectiva (sus casas, el río, la huerta y la escuela primaria) y d) La construcción de sentido y significado de estos lugares para que la descendencia femenina los use en condiciones de equidad.

Apoyadas en estos mecanismos, estas mujeres se movilizaron con repertorios convencionales y disruptivos, como los que se muestran en la Tabla 2. Se subraya la visita de Angela Davis, un encuentro con mujeres del África afectadas por la AngloGold Ashanti y la participación en una vigilia que se realiza anualmente en Estados Unidos en contra de la Escuela de las Américas ${ }^{1}$. Repertorios que dan cuenta de la cercanía de estas mujeres con procesos y organizaciones internacionales, que permiten visibilizarse, hacer presión para conseguir sus metas reivindicativas y sensibilizar la opinión pública. En este proceso se fue definiendo que los principales oponentes eran el Ejecutivo, grupos armados y los mineros ilegales. Entre los aliados influyentes identificados se pueden

1 Según la publicación Observatorio de la Escuela de las Américas en su portal "Soawlatino.org", Colombia ha graduado a más de 10.446 militares y supera a todos los países capacitados por la escuela, en lista sigue Perú con 4.559 y Nicaragua con 4.529 militares graduados. 
enumerar los hombres de su propia comunidad, las organizaciones de jóvenes, mujeres $\mathrm{y}$ derechos humanos de tipo local regional $\mathrm{y}$ nacional, los sindicatos, algunos congresistas como Iván Cepeda, Alberto Castilla y medios de comunicación. Además, se logró desarrollar las movilizaciones femeninas en un periodo de efervescencia de la protesta social protagonizada por: cafeteros, campesinos, maestros, estudiantes, profesionales de la salud, mujeres, defensores de los derechos civiles y democráticos, entre otros.

En noviembre cuando salimos y diciendo "es que las mujeres como parimos, estamos defendiendo la vida y los territorios ancestrales y estamos denunciando la minería ilegal" le estábamos diciendo al Estado que tiene una responsabilidad y que la está omitiendo. Entonces, cuando actores armados nos declaran objetivo militar por qué nos oponemos a ese tipo de minería, por qué nos oponemos a que la vida de nuestra comunidad, -la vida como yo le he explicado- se esté acabando, es con la misma complicidad del mismo Estado (entrevista 3, lideresa de la Organización de Mujeres de La Toma y del Consejo Comunitario).

Con esto ellas logran la articulación entre mujeres como medio para deconstruir los modelos de violencia, exclusión e inequidad e imponer los propios, basados en la garantía de la vida en todas sus expresiones, el amor, la maternidad y los derechos humanos. Finalmente, esta reflexión evidencia cómo la identidad de género y la étnica marcan, de manera significativa, las motivaciones y los repertorios de acción de las mujeres de La Toma. Estableciendo relaciones entre la historia africana, el proceso esclavista, la libertad ganada, la configuración de la feminidad en el Occidente, la vulneración al derecho fundamental de la vida y la nueva emancipación femenina por la protección de su comunidad.

Los tiempos que dedican a las tareas de movilización dependen del tiempo que dejen libre las labores domésticas, laborales o de acompañamiento a otros familiares. La interpretación que hacen de la lucha, como un producto de la historia, de las conquistas de sus ancestros y los derechos étnicos, se libra para las generaciones venideras. Sus marcos de referencia son el agua, la vida, las tradiciones ancestrales, el territorio, la identidad negra y la maternidad se acompañan con la exhibición de sus símbolos: la presencia de sus hijos en los lugares de concentración, los turbantes, el afro, las trenzas y los colores de las pancartas.

La demanda por la tierra y la defensa del territorio poseen una disparidad entre actores sociales que implica una relevante diferencia, mientras que la primera está asociada con la lucha de un campesinado negro que considera la tierra como un medio de producción que garantiza la reproducción familiar; la segunda implica la construcción de un actor que genera una identificación emocional con un espacio que construye como territorio (Casti- 
llo, 2010). A pesar de la diferenciación serán explicados a continuación. La Tabla 2 muestra que los repertorios de acción por la defensa del territorio son los más recurrentes. Analizando su composición, la mayor parte corresponde a bloqueos de carreteras y a toma de instalaciones, lo que deduce un continuo cálculo sobre el costo/beneficio, el cual condiciona el tipo de acción colectiva con la probabilidad de ganancia en las demandas hechas. Estas acciones se realizan en compañía de la comunidad y son lideradas por los hombres. Según Eveline y Booth (2002) es preciso hacer dichas salvedades, en la medida que las acciones colectivas emprendidas únicamente por mujeres, no son de tipo confrontativo, esto debido a un continuo desprendimiento de la violencia como forma de protesta. Las promueve la creación de una cultura de paz con sentadas, plantones, boicots, vigilias, entre otras formas de llamar la atención. La primera consideración es que estas dos formas de protestar son el recurso más vasto para que las demandas sean escuchadas. En la acción disruptiva la regla general es romper con la cotidianidad, sorprender a los observadores y desafiar al oponente (Tarrow, 1994).

Otra motivación que encontraron las mujeres de La Toma para movilizarse fue la presencia de actores armados que perjudicaban gravemente las condiciones de vida de la comunidad y violan los derechos humanos. Estos grupos se enfrentan para dirimir el dominio de las minas de oro y en consecuencia ubican en la línea de fuego la vida de los pobladores. Con su presencia, los jóvenes se exponen al reclutamiento forzado y las mujeres a la violencia sexual y a las amenazas de muerte que reciben a raíz del rol protagónico. La motivación más influyente para la movilización es la defensa de los Derechos Humanos. En la Tabla 2 se muestran movilizaciones/plantones, alocuciones públicas, homenajes a fallecidos, encuentros y otros. Su propósito es denunciar su vulnerabilidad.

Aunque en principio no plantearon derechos específicos como mujeres, la vivencia cotidiana con los desafíos impuestos a su género, la disputa por el poder al interior del Consejo Comunitario y la cercanía con organizaciones y lideresas feministas, las fue llevando hacia un discurso que incorpora cuestiones del feminismo negro, de la equidad de género y del "poder maternal", para negociar con políticos o con entidades del Estado. Con esta representación existe la posibilidad de crear micropoderes comunitarios.

Respecto a los espacios para la acción colectiva, la revisión documental y sus testimonios evidencian que la movilización se desarrolla sobre todo en recintos cerrados (edificaciones oficiales, escuelas, universidades y coliseos). También tuvieron despliegue en espacios públicos como calles, plazas, parques, "edificios públicos-estatales" o carreteras. Estos fueron escenarios propicios para la consecución de aliados influyentes o por la inclinación de las organizaciones de mujeres para resolver sus demandas en espacios institucionales de deliberación política. 
Sobre los aliados en la movilización se puede señalar que fueron diversos. Como señala Jabardo (2012), desde el principio de sus luchas, las mujeres negras fueron extraordinariamente lúcidas a la hora de posicionarse y fuertes a la hora de establecer alianzas con los hombres de su propia 'raza' en las antiguas comunidades de esclavos, con las mujeres blancas en la lucha por el sufragio femenino y, sobre todo, con sus "hermanas" negras cuando diversos factores incorporaron las diferencias de género a las comunidades negras (2012). Del mismo modo Tarrow argumenta que los aliados sirven de amigos en los tribunales, garantes contra la represión o como negociadores aceptables (Tarrow, 1994).

Entre los principales aliados se destacan: a) Los aliados étnicos y comunitarios: Consejo Comunitario de La Toma, La Guardia Cimarrona y los hombres jóvenes del Consejo Comunitario, b) Las organizaciones de mujeres, redes, plataformas, colectivos, el movimiento de mujeres y feminista, sobresalen entre estas: La Asociación Casa Cultural del Chontaduro y el Comité de Mujeres Corteras de Caña, c) Las organizaciones internacionales de apoyo a las demandas étnicas y de género, permitieron ser visibles en otros escenarios y sensibilizar la opinión pública. Se destacan la académica Angela Davis, el grupo de afectados la AngloGold en África. Estos aliados permitieron su presencia en la Vigilia en Estados Unidos contra de la Escuela de las Américas, tres giras por universidades de Estados Unidos y la invitación de Francia Márquez en la V Delegación de Víctimas en La Habana, Cuba. Estos aliados son el principal benefactor o patrocinador de sus movilizaciones, d) Los partidos de izquierda y los sindicatos y congresistas como Iván Cépeda, Alberto Castilla y Clara López, del Polo Democrático Alternativo, el congresista del partido MAIS Luis Andrade y los sindicatos ANTHOC y SINTRAENAL ${ }^{2}$.

Y e) Los aliados institucionales, que a pesar que los canales institucionales políticos están disponibles a todos los ciudadanos, para estas mujeres fueron muy importantes los apoyos logrados por algunos funcionarios del Estado, que contribuyeron a promover $y$ agilizar sus demandas. El aporte más valioso fue el de la Corte Constitucional y la Defensoría del Pueblo.

\section{Reflexiones Finales}

En la acción colectiva que desarrollaron las mineras de La Toma se destaca la creatividad de las mujeres negras, para idear nuevas formas organizativas, potenciar nuevos liderazgos y crear y recrear marcos de significado ligados a su quehacer cotidiano, a sus costumbres y su cultura como pueblo negro que defiende su territorio. Por ello, en los repertorios de acción que usan siempre recurren a la expresión de sus sentimientos, de su emotividad, de las evo-

\footnotetext{
2 ANTHOC: Asociación Nacional Sindical de Trabajadores y Servidores Públicos de la Salud, Seguridad Social Integral y Servicios Complementarios de Colombia. SINTRAENAL: Sindicato de Empleados y Trabajadores de la Educación.
} 
caciones que provoca su vínculo con el territorio y la vida que se produce en él.

Su salida a la arena política, la integración a otras plataformas de mujeres, su relación con activistas de otras organizaciones y movimientos sociales han fortalecido su liderazgo interno y han visibilizado sus luchas dentro y fuera del territorio. Esto también les ha permitido una mejor lectura de su situación y estar atentas a las oportunidades políticas. Para ello se han valido de aliados poderosos, que han contribuido a mitigar el riesgo que afrontan en su puesta en escena, ante oponentes que no solo usan recursos legales, sino la violencia física para amedrentarlas y hacerlas desistir de sus reivindicaciones.

Hoy, ellas son reconocidas como sujetos políticos que defienden su territorio y la vida, que hacen demandas por el acceso a la tierra, que denuncian con vehemencia las amenazas contra sus cuerpos y que han expuesto la dramática situación que viven los mineros ancestrales en un país rico en recursos naturales, que los explota sin calcular los daños ambientales y culturales.

Por supuesto, esta participación política ha tenido muchos contradictores y no ha sido fácil, pero las mineras de La Toma siguen su lucha, porque su resistencia ha sido ejemplarizante y ya los réditos personales y colectivos se están capitalizando en sus organizaciones comunitarias.

\section{Referencias bibliográficas}

Ararat, L., Mina, E., Rojas, A., Solarte, A.M., Vanegas, G., Vargas, L.A. \& Vega, A. (2013). La Toma. Historias de territorio, resistencia y autonomía en la cuenca del Alto Cauca. Bogotá: Observatorio de Territorios Étnicos-Pontificia Universidad Javeriana/Consejo Comunitario Afrodescendiente del corregimiento de $\mathrm{La}$ Toma.

Bernasconi, A. (2014). Afro-Descendant Resistance (Doctoral dissertation). University of Fribourg.

Brah, A. (2011). Cartografías de la diáspora: identidades en cuestión. España: Editorial Traficantes de Sueños.

Cardona, A. (2012). De señores de la tierra a señores de la mina. Minería, marcos normativos y conflictos. Bogotá: CINEP.

Castillo, L.C. (2010). Etnicidad, acción colectiva y resistencia: el Norte de Cauca y el Sur del Valle a comienzos del siglo XXI. Programa Editorial Universidad del Valle Programa Editorial.

Davis, A. (1981). El legado de la esclavitud: modelos para una nueva feminidad. Mujeres, raza y clase, 11-37.

Delgado, G.C. (2010). Ecología política de la minería en América Latina. México: Centro de Investigaciones Interdisciplinarias en Ciencias y Humanidades. UNAM.

Departamento Nacional de Planeación (2010). Plan Nacional de Desarrollo 2010-2014 al Honorable Congreso de la República de Colombia. Recuperado de https://www. 
dnp.gov.co/Plan-Nacional-de-Desarro1lo/PND-2010-2014/Paginas/Plan-Nacional-De-2010-2014.aspx

Eveline, J. \& Booth, M. (2002). Gender and sexuality in discourses of managerial control: The case of women miners. Gender, Work \& Organization, 9(5), 556-578.

Gobernación del Cauca (2010). Plan Departamental de Desarrollo 2002-2006 a la Honorable Asamblea Departamental del Cauca. Recuperado de http://www.cauca.gov.co/etiquetas/plan-de-desarrollo

Guzmán, Á. \& Rodríguez, A.N. (2014). Reconfiguración de los órdenes locales y conflicto armado: el caso de tres municipios del Norte del Cauca (1990-2010). Revista Sociedad y Economía, (26).

Hernández, E. (2009). Resistencias para la paz en Colombia. Experiencias indígenas, afrodescendientes y campesinas. Revista de Paz y Conflictos, (2).

Hernández, J. (2002). La resistencia civil en caliente: una contribución a la pacificación del conflicto en Colombia. Revista Sociedad y Economía, (2).
Herrera, L., García, M., Coronado, S., Cadena, A., Figueroa, M. \& Yepes, A. (2012). Minería, conflictos sociales y violación de derechos humanos en Colombia. Bogotá: CINEP.

Jabardo, M. (2012). Feminismos negros. Una antología. España: Editorial Traficantes de Sueños.

Macuacé, R.A. \& Cortés, R. (2013). El Cauca, la mesoeconomía del oro y la retroactividad de la dependencia: anotaciones sobre coyuntura y desequilibrio territorial. Civilizar. Ciencias Sociales y Humanas, 13(25).

Osorio, C. (2010). El Legado minero de Uribe. Bogotá. La Silla Vacía. Recuperado de http://lasillavacia.com/historia/18648

Sentencia T-1045A/10. Corte Constitucional de Colombia. Colombia, Bogotá. 14 de diciembre del 2010.

Tarrow, S. (1994). El poder en movimiento. Los movimientos sociales, la acción colectiva y la política. Madrid: Alianza. 